\title{
NT-proBNP as a marker of intraoperative fluid balance.
}

\author{
Kamnev S, Malakhova A, Kopycheva N, Noskova K, Subbotin V \\ Moscow Clinical Scientific Center, Dept of Anesthesiology \\ and Intensive Care, Russia
}

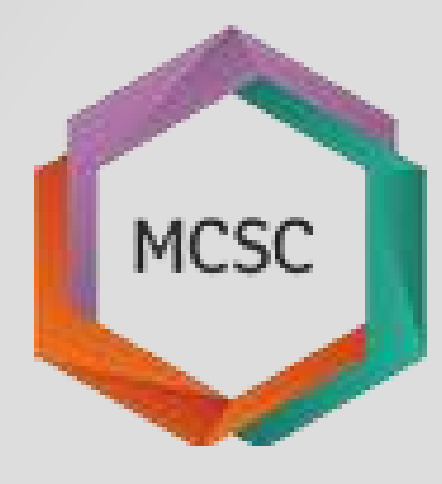

Background and Goal of Study: It is important periodically to calculate actual fluid volume status during surgery. Knowledge of actual fluid volume status could influence on management of fluid and vasopressor therapy, especially in case of instable hemodynamics and ongoing bleeding. Many studies presented that fluid loading increases NT-proBNP $(1,2)$. We have a hypothesis that NT-proBNP could be a biomarker of fluid loading and its changes could correlate with changes of fluid balance.

Materials and Methods: Our study was powered to reveal only strong correlation ( $r>0,7$ ). A total of 21 patients without significant heart diseases undergoing abdominal surgery were enrolled. NT-proBNP was obtained in the operation room before any infusion and at the end of the 4th hour of anesthesia (this was usually the main stage of the surgery). At that moment total intravenous infusion, diuresis, blood loss and fluid volume status were calculated. Blood loss was calculated based on gravimetric method.

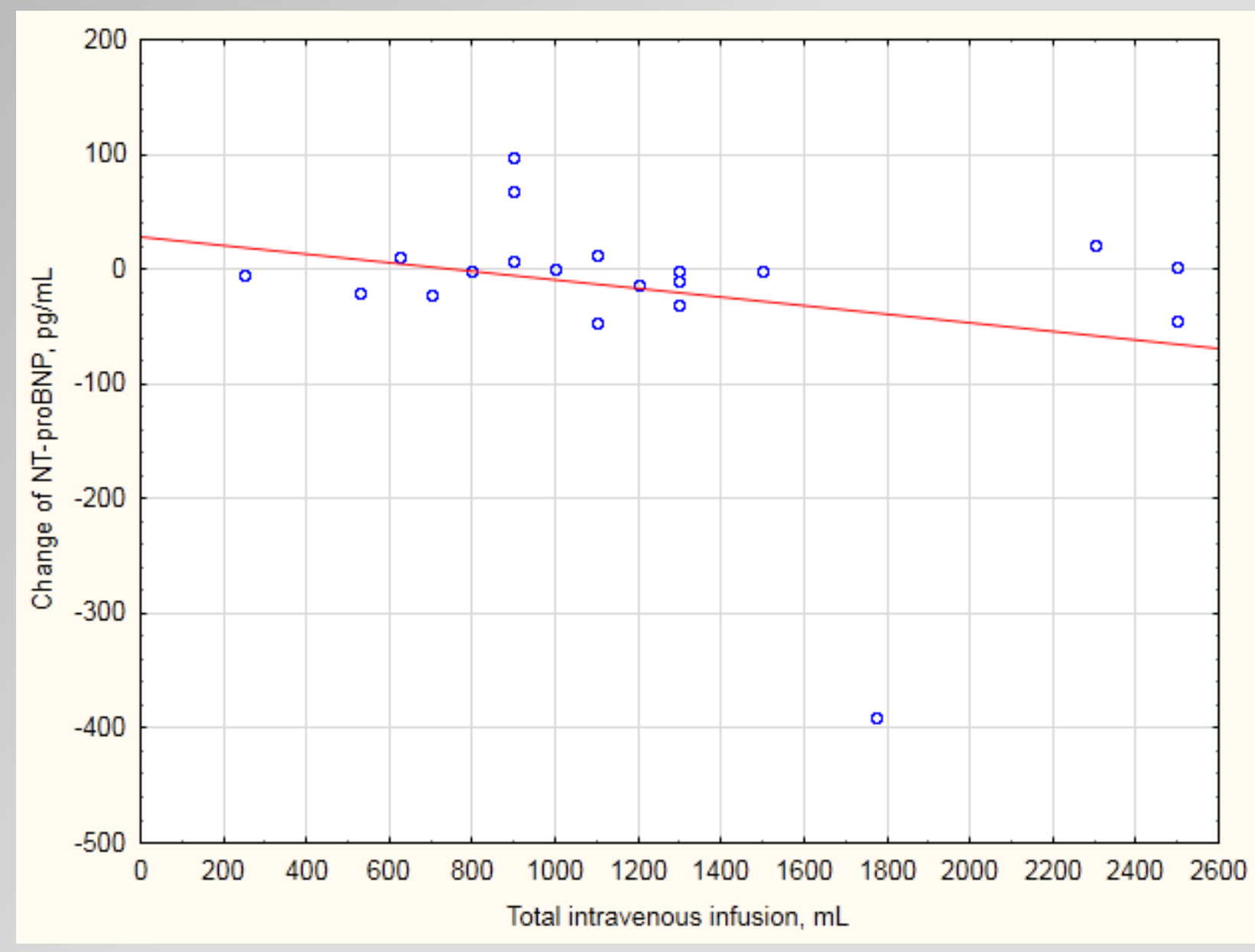

Spearman correlation coefficients between $\triangle N T$-proBNP and total intravenous infusion, fluid volume balance and rate of infusion were $-0,176,0,136$ and $-0,233$ respectively (all insignificant). Actual power for this correlations was low.

Obtained data may be explained by using mainly restrictive fluid strategy during abdominal surgery in our hospital. So there is no volume loading and big volume shift during surgery.

Conclusion: NT-proBNP failed to show significant correlation with changes of fluid volume status during abdominal surgery in case of restrictive fluid strategy.

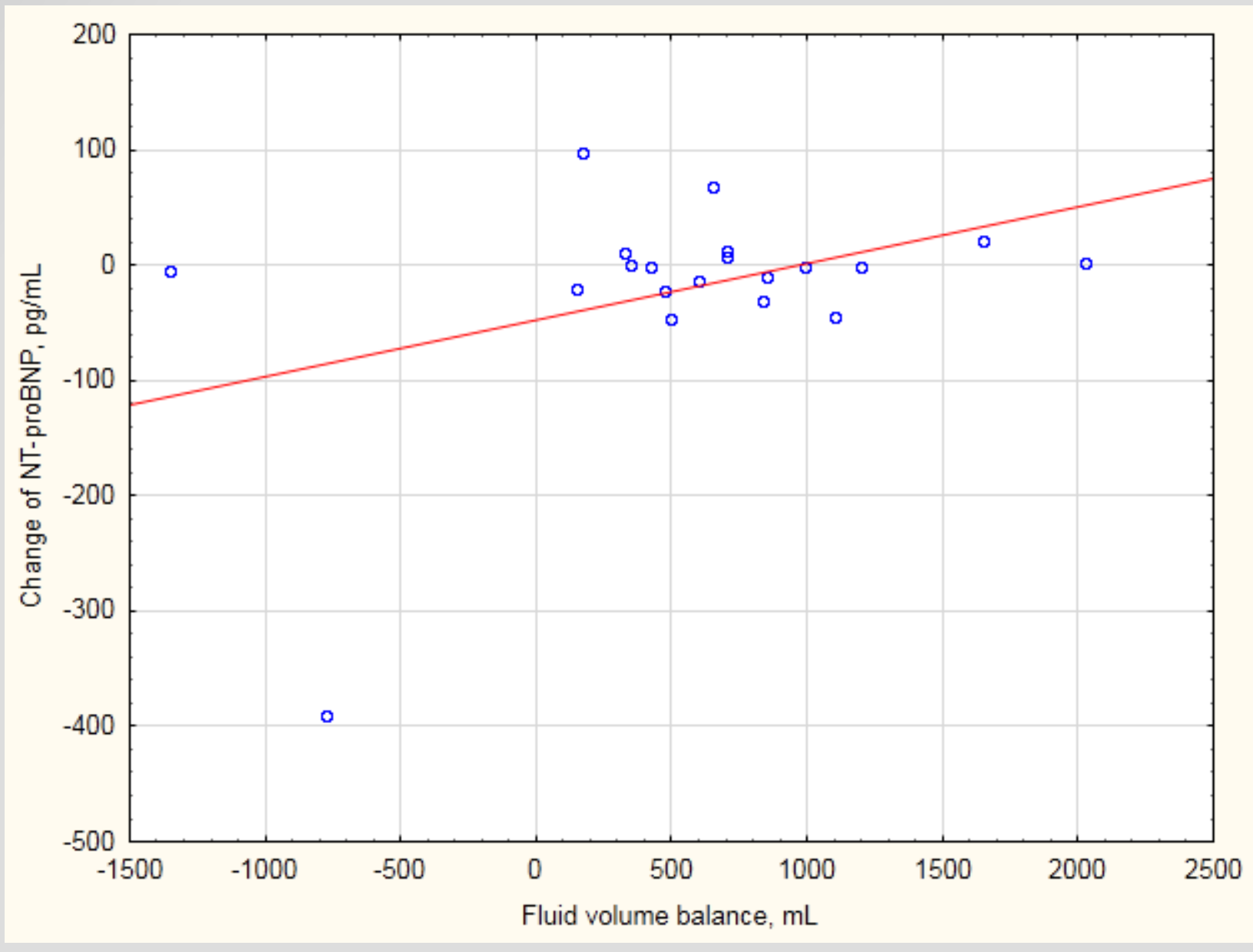

Results and Discussion: Median and [interquartile range, IQR] of NT-proBNP was $88,9 \mathrm{pg} / \mathrm{mL}$ [25,3;165] at the beginning and $74,7 \mathrm{pg} / \mathrm{mL}[24,3 ; 164]$ at the end of the 4th hour. The difference between measurements was insignificant $(p=0,3)$ and underpowered (calculated power $=13 \%$ ). Change of NT-proBNP ( $\triangle N T$-proBNP) was $-1,7$ $\mathrm{pg} / \mathrm{mL}[-21,3 ; 7,7]$.

After 4 hours total intravenous infusion was $1100 \mathrm{~mL}$ [900;1300], diuresis was $300 \mathrm{~mL}$ [240;500] and blood loss was $100 \mathrm{~mL}$ [70;150]. Fluid volume balance after 4 hours was $650 \mathrm{~mL}$ [350;990]. Rate of infusion was $3,8 \mathrm{~mL} / \mathrm{kg} / \mathrm{h}$ $[2,6: 4,7]$.

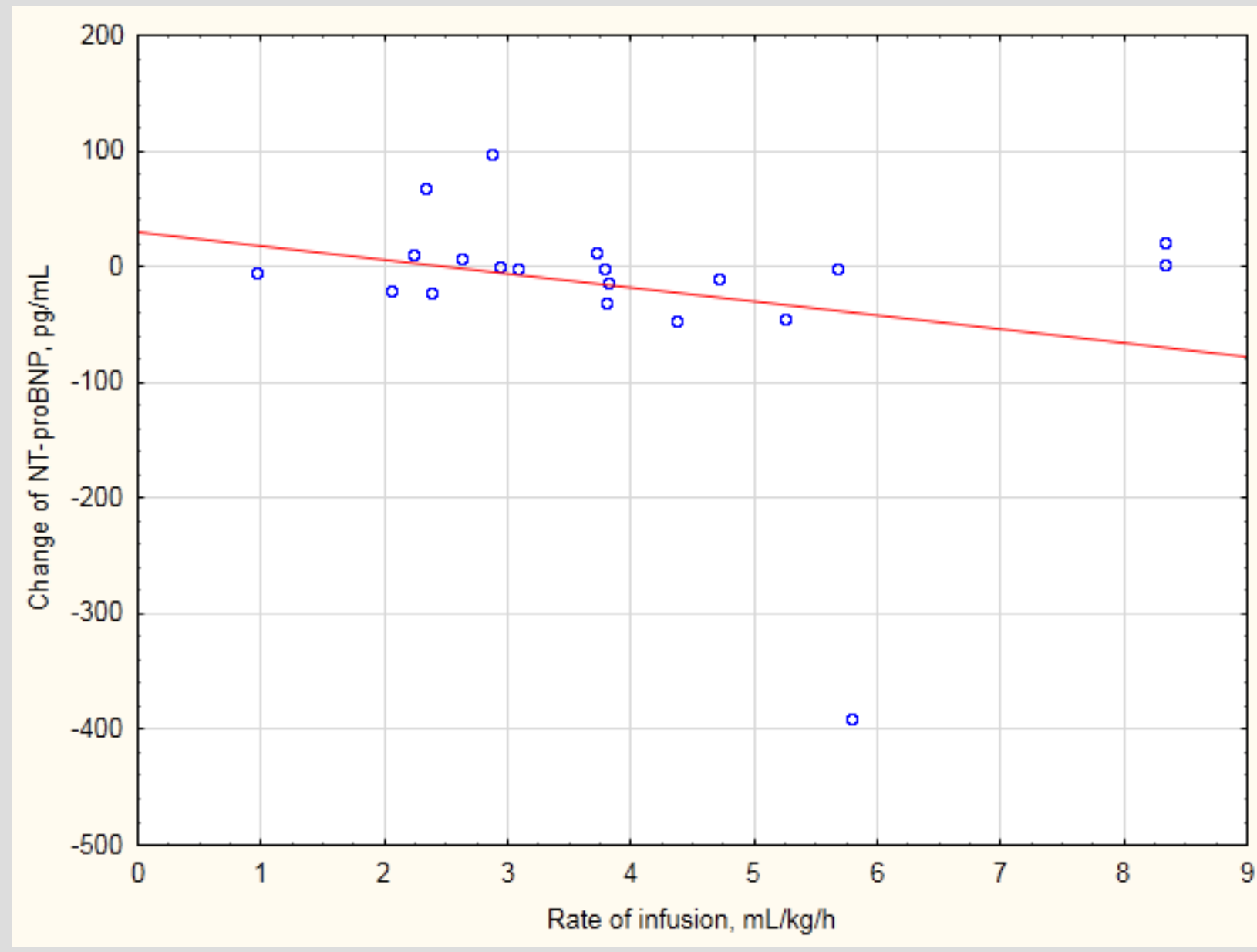

